\title{
Usefulness of meshed SurgiMend in direct-to-implant breast reconstruction
}

\author{
Pil Seon Eo ${ }^{1}$, Joon Seok Lee, \\ Jeong Woo Lee ${ }^{1}$, Kang Young Choi ${ }^{1}$, \\ Ho Yun Chung ${ }^{1}$, Byung Chae Cho ${ }^{1}$, \\ Jeeyeon Lee', Ho Yong Park², \\ Jung Dug Yang ${ }^{1}$ \\ Departments of ${ }^{1}$ Plastic and \\ Reconstructive Surgery and ${ }^{2}$ Surgery, \\ School of Medicine, Kyungpook National \\ University, Daegu, Korea
}

\begin{abstract}
Background The use of acellular dermal matrix in implant-based breast reconstruction immediately after mastectomy has attracted attention in recent years because it yields good outcomes. Herein, we analyzed the usefulness of meshed SurgiMend in direct-toimplant (DTI) breast reconstruction.

Methods In this retrospective single-center analysis, 44 one-stage breast reconstructions using SurgiMend were performed in 42 patients from May 2016 to December 2017. The implant was inserted into the subpectoral plane and SurgiMend was applied to the inferolateral part that lacked tissues to wrap the silicone implant. In 19 patients (20 breasts), fenestration was performed with SurgiMend, while in the remaining 23 patients (24 breasts), SurgiMend that was meshed at a ratio of 1:1.5 was used. We analyzed the frequency of complications. Patient satisfaction was compared and analyzed using a five-item questionnaire (shape, texture, symmetry, pain, and overall outcome). Results The average age of the patients was 43.2 years, and their mean body mass index was $21.1 \mathrm{~kg} / \mathrm{m}^{2}$. The average follow-up period was 24.0 months. In the control (fenestrated SurgiMend) and experimental (meshed SurgiMend) groups, major seroma occurred in five of the 20 breasts (25.0\%) and two of the 24 breasts (8.3\%), respectively. Minor complications were resolved with conservative treatment. The patient satisfaction score for shape, texture, symmetry, pain, and overall satisfaction was 4.3, 4.1, 4.7, 4.5 , and 4.4 , respectively.

Conclusions Applying meshed SurgiMend in DTI breast reconstruction is a useful surgical technique.
\end{abstract}

Keywords Breast implants / Acellular dermis / Surgical mesh / SurgiMend

\section{INTRODUCTION}

Implant-based breast reconstruction after mastectomy is becoming more common because it has several advantages. It is a simpler surgical procedure than other methods, such as breast reconstruction using flaps, and it allows faster patient recovery with no addi-

Received: Oct 13, 2020 Revised: Nov 30, 2020 Accepted: Dec 9, 2020 Correspondence: Jung Dug Yang Department of Plastic and Reconstructive Surgery, School of Medicine, Kyungpook National University, 130 Dongdeokro, Jung-gu, Daegu 41944, Korea

Tel: +82-53-420-5681, Fax: +82-53-425-3879, E-mail: lambyang@knu.ac.kr

Copyright $\odot 2021$ The Korean Society for Aesthetic Plastic Surgery.

This is an Open Access article distributed under the terms of the Creative Commons Attribution Non-Commercial License (https://creativecommons.org/licenses/by-nc/4.0/) which permits unrestricted non-commercial use, distribution, and reproduction in any medium, provided the original work is properly cited. www.e-aaps.org tional scars [1]. However, implants are placed below the pectoralis major muscle because complications such as infection, capsular contracture, and explantation are likely to occur when implants are directly exposed [2-5]. After acellular dermal matrix (ADM) was developed in 2005, surgery with inferolateral tissue support has been performed to compensate for the disadvantages of total muscle coverage [6-8]. Despite the advantages of ADM such as good cosmetic outcomes, additional reinforcement, improved implant positioning, and a reduced risk of capsular contracture [9], seroma, infection, and inflammation are possible when ADM is used, and $\mathrm{ADM}$ also has the disadvantage of a high cost [10]. Surgery using $\mathrm{ADM}$ fenestration is widely performed because previous studies have reported that this technique leads to better cosmetic outcomes, results in fewer complications such as seroma, and stimulates biointegration [11-15]. However, fenestrating ADM during surgery can be cumbersome because the surgeon has to make pores one by 
one using tools such as a blade, and making equally spaced and identically shaped pores is difficult. Although fenestrated ADM products like SurgiMend and SurgiMend PRS are commercially available, there are certain limitations in expanding the material because these products have relatively small and widely spaced pores.

SurgiMend is produced from fetal bovine dermis and is mainly composed of type I/III collagen. SurgiMend is widely used throughout the world in implant-based breast reconstructions because of its superiority in terms of tensile strength, suture retention strength, and tear resistance compared to other ADMs produced from porcine tissue with similar thickness [16]; furthermore, it is very similar to human ADM [17] and is used globally in breast reconstruction using implants [18]. Therefore, in this study, we analyzed the usefulness of meshed SurgiMend, which was processed using a skin graft mesher in direct-to-implant (DTI) breast reconstruction.

\section{METHODS}

This retrospective single-center study was conducted with $42 \mathrm{pa}$ tients (44 breasts) who underwent one-stage breast reconstruction using SurgiMend (SurgiMend 1.0; TEI Biosciences Inc., Boston, MA, USA) from May 2016 to December 2017. All breast reconstructions were performed by a single plastic surgeon (JDY).

A total of 23 patients (24 breasts) underwent surgery with ADM meshed at a 1:1.5 ratio using a skin graft mesher (Zimmer Surgical Inc., Warsaw, IN, USA), and manually fenestrated ADM using a no. 11 blade was inserted in 19 patients (20 breasts) in the control group (Fig. 1).

Patients' breast size (width, height, and projection) was assessed preoperatively using the taping and molding method to determine the appropriate shape and size of the implant. Immediate breast reconstruction was performed immediately after mastectomy was conducted by a general surgeon, and the implant was inserted into the subpectoral plane after detaching the pectoralis major muscle. Meshed or fenestrated SurgiMend was used in all patients to cover the inferolateral part, where the silicone implant was exposed outside the pectoralis major muscle (Fig. 2).

The inclusion criteria were as follows: patients aged $>18$ years who underwent implant-based breast reconstruction after mastectomy, had breast cancer without systemic metastasis, were not pregnant or breastfeeding, and had completed 3 months since their last session of radiotherapy or chemotherapy to treat breast cancer. The following patients were excluded: those with systemic metastasis of breast cancer, those who had undergone radiotherapy or chemotherapy within the last 3 months, and smokers.

The following characteristics of patients were assessed: age, height, weight, whether they underwent radiotherapy or chemotherapy preoperatively or postoperatively, size of breasts, and weight of the mass removed by mastectomy. Furthermore, the incidence of postoperative complications such as hematoma, seroma, and infection was evaluated, and patients' subjective satisfaction was assessed within 1 year postoperatively using the Breast Reconstruction Satisfaction Questionnaire regarding shape, texture, symmetry, pain, and general satisfaction.

Statistical analysis was performed using SPSS Subscription version 1.0 (IBM Corp. Armonk, NY, USA), and the Fisher exact test was used. A P-value of $<0.05$ was considered to indicate statistical significance.

All procedures performed in studies involving human partici-
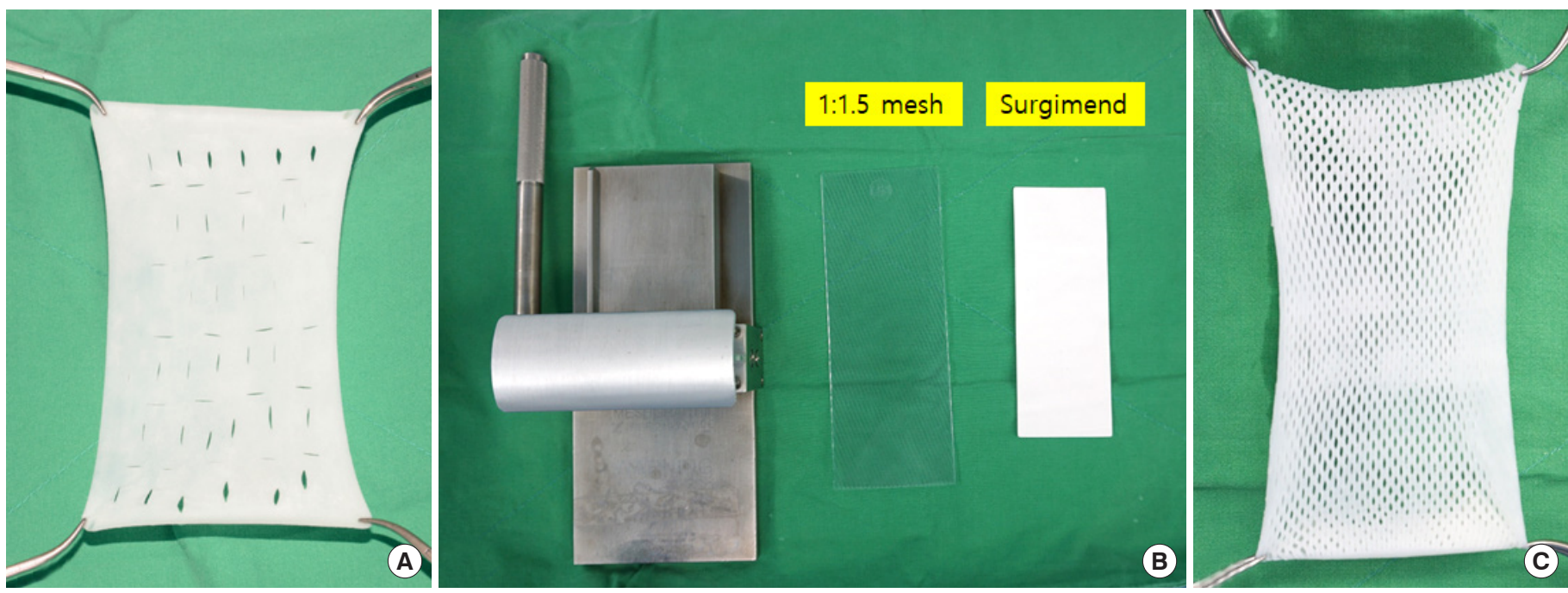

Fig. 1. Photos of skin mesher and SurgiMend. (A) A photo of SurgiMend cut using a no. 11 blade. (B) A photo of skin mesher, 1:1.5 mesh, SurgiMend (left to right). (C) A photo of stretched meshed SurgiMend. The meshed SurgiMend was prepared using a skin mesher (1:1.5). The acellular dermal matrix was expanded from side to side. 

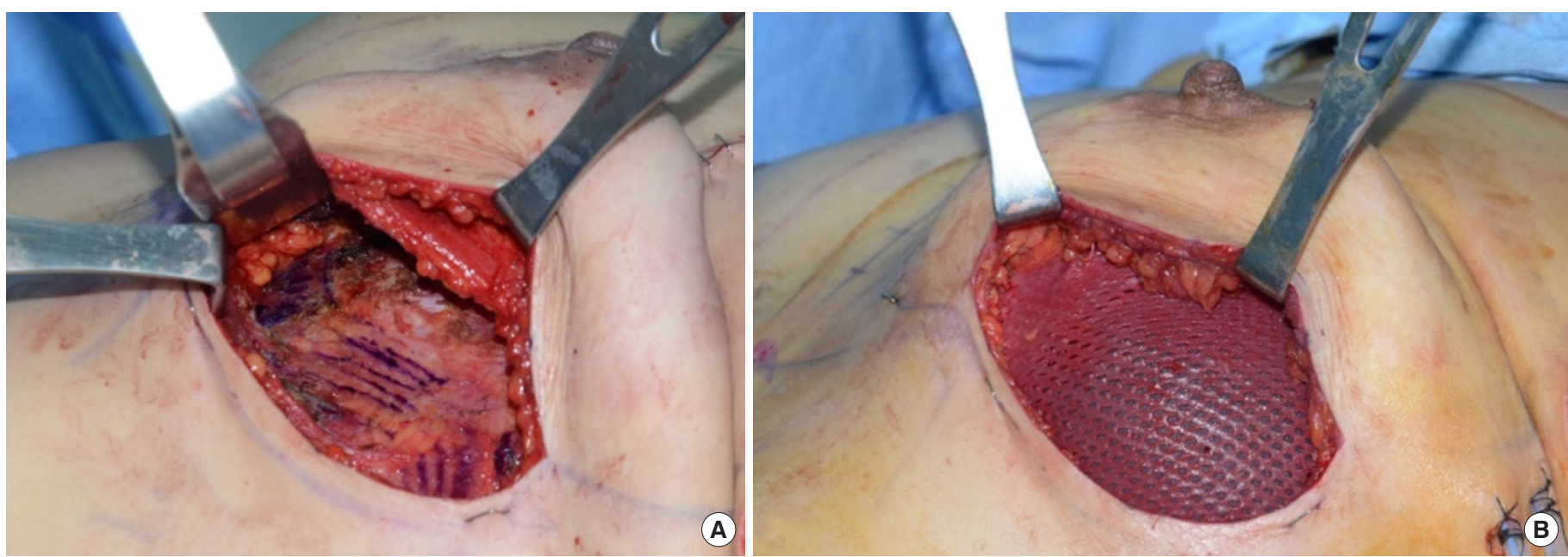

Fig. 2. Intraoperative findings of a 37-year-old patient with left breast cancer. (A) A picture taken as the pectoralis major flap approached the inframammary fold after skin-sparing mastectomy and elevation. (B) A picture taken when the silicone implant (MENTOR CPG 311; 235 cC) was inserted into the subpectoral plane and the meshed SurgiMend $\left(6 \times 12 \mathrm{~cm}^{2}\right)$ was applied to the inferolateral area that lacked tissues.

pants were in accordance with the ethical standards of the institutional and/or national research committee and with the 1964 Declaration of Helsinki and its later amendments or comparable ethical standards. This study was approved by the Institutional Review Board (IRB) (IRB No. 2020-03-006). Written informed consent was obtained from the patients for the publication of this study and any accompanying images.

\section{RESULTS}

\section{Patients' characteristics}

In the control group, the average age was $45.7 \pm 3.1$ years, the mean body mass index (BMI) was $22.1 \pm 1.2 \mathrm{~kg} / \mathrm{m}^{2}$, the preoperative breast volume was $329.5 \pm 68.3 \mathrm{cc}$, and the mass excised during mastectomy was $305.1 \pm 80.9 \mathrm{~g}$. The mean length of the follow-up period was 27.7 months, and three (15.0\%) and four patients (20.0\%) underwent adjuvant radiotherapy and adjuvant chemotherapy, respectively. In the experimental group, the average age was $43.2 \pm 3.8$ years, the mean BMI was $21.1 \pm 1.0 \mathrm{~kg} / \mathrm{cm}^{2}$, the preoperative breast volume was $263.3 \pm 39.5 \mathrm{cc}$, and the mass excised during mastectomy was $231.3 \pm 28.7 \mathrm{~g}$. The average length of the follow-up period was 24.0 months, and four (16.0\%) and seven patients (29.2\%) underwent adjuvant radiotherapy and adjuvant chemotherapy, respectively. No statistically significant differences were observed between the groups (Table 1).

\section{Complications}

In the control group, five patients (25.0\%) had seroma, three (15.0\%) had red breast syndrome, one (5.0\%) had mild hematoma, and four $(20.0 \%)$ had linear skin necrosis. Red breast syndrome was defined as localized erythema at the operation site observed for
Table 1. Patients' characteristics

\begin{tabular}{lccc}
\hline Characteristics & $\begin{array}{c}\text { Control group } \\
(\mathrm{n}=20)\end{array}$ & $\begin{array}{c}\text { Experimental } \\
\text { group }(\mathrm{n}=24)\end{array}$ & P-value \\
\hline Age (yr) & $45.7 \pm 3.1$ & $43.2 \pm 3.8$ & 0.295 \\
Body mass index $\left(\mathrm{kg} / \mathrm{m}^{2}\right)$ & $22.1 \pm 1.2$ & $21.1 \pm 1.0$ & 0.192 \\
Preoperative breast volume $(\mathrm{cc})$ & $329.5 \pm 68.3$ & $263.3 \pm 39.5$ & 0.090 \\
Mastectomy mass weight $(\mathrm{g})$ & $305.1 \pm 80.9$ & $231.3 \pm 28.7$ & 0.061 \\
Follow-up period $(\mathrm{mo})$ & 27.7 & 24.0 & 0.273 \\
Smokers & None & None & - \\
Adjuvant radiotherapy & $3(15.0)$ & $4(16.7)$ & 0.775 \\
Adjuvant chemotherapy & $4(20.0)$ & $7(29.2)$ & 0.247 \\
\hline
\end{tabular}

Value are presented as mean $\pm S D$, average, or number $(\%)$.

days or weeks postoperatively without any sign of systemic infection [19-21]. In the experimental group, two patients (8.3\%) had seroma, three (12.5\%) had red breast syndrome, two (8.3\%) had mild hematoma, and three (12.5\%) had linear skin necrosis. Seroma was defined based on both suspicion in a postoperative physical examination and observation on ultrasonography (USG); all patients showed improvement in symptoms after USG-guided aspiration. Other complications, such as hematoma and skin necrosis, showed improvement after conservative management. One patient in the experimental group underwent explantation and autologous breast reconstruction due to implant malpositioning.

The incidence of seroma was lower in the experimental group (8.3\%) than in the control group (25\%), although the difference was not statistically significant $(\mathrm{P}=0.137)$. Red breast syndrome, hematoma, and linear skin necrosis rate did not show statistically significant between-group differences, and neither infection or inflammation was observed in either group (Table 2). 
Table 2. Complications

\begin{tabular}{lccc}
\hline Complications & $\begin{array}{c}\text { Control group } \\
(\mathrm{n}=20)\end{array}$ & $\begin{array}{c}\text { Experimental } \\
\text { group }(\mathrm{n}=24)\end{array}$ & P-value \\
\hline Seroma & $5(25.0)$ & $2(8.3)$ & 0.137 \\
Infection, inflammation & None & None & - \\
Red breast syndrome & $3(15.0)$ & $3(12.5)$ & 0.812 \\
Mild hematoma & $1(5.0)$ & $2(8.3)$ & 0.666 \\
Linear skin necrosis & $4(20.0)$ & $3(12.5)$ & 0.503
\end{tabular}

Value are presented as number (\%).

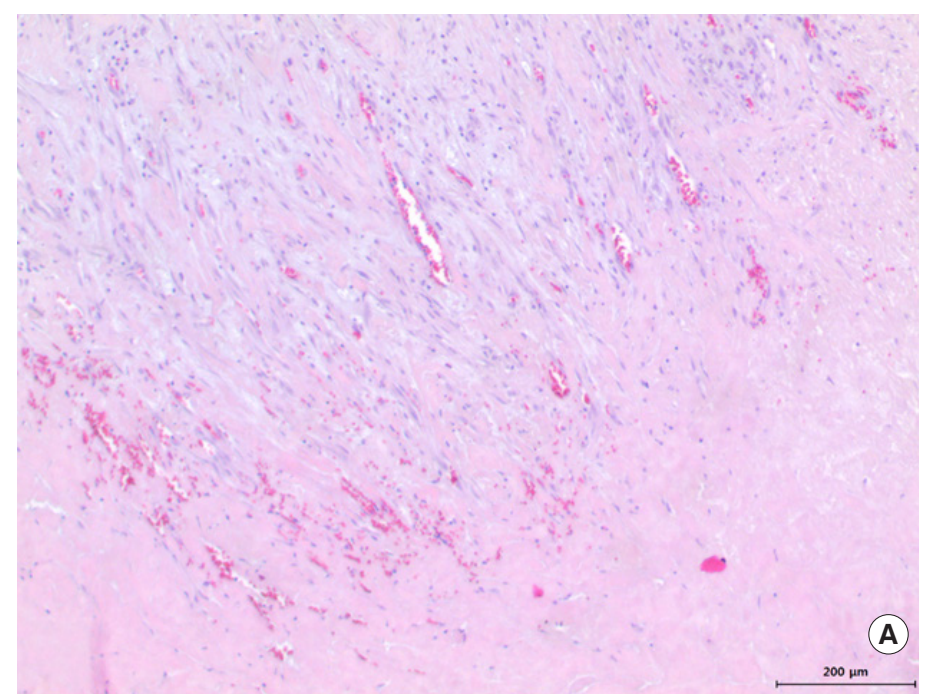

Table 3. Questionnaire results at postoperative 1 year

\begin{tabular}{lccc}
\hline \multirow{2}{*}{ Variable } & \multicolumn{2}{c}{ Score, mean \pm SD } & P-value \\
\cline { 2 - 3 } & $\begin{array}{c}\text { Experimental } \\
\text { group }\end{array}$ & $\begin{array}{c}\text { Control } \\
\text { group }\end{array}$ & \\
\hline Shape & $4.3 \pm 0.8$ & $4.3 \pm 0.3$ & $>0.05$ \\
Texture & $4.1 \pm 0.6$ & $4.0 \pm 1.2$ & \\
Symmetry & $4.7 \pm 0.7$ & $4.6 \pm 0.5$ & \\
Pain & $4.5 \pm 0.7$ & $4.2 \pm 0.6$ & \\
Overall outcome & $4.4 \pm 1.1$ & $4.3 \pm 0.8$ & \\
\hline
\end{tabular}

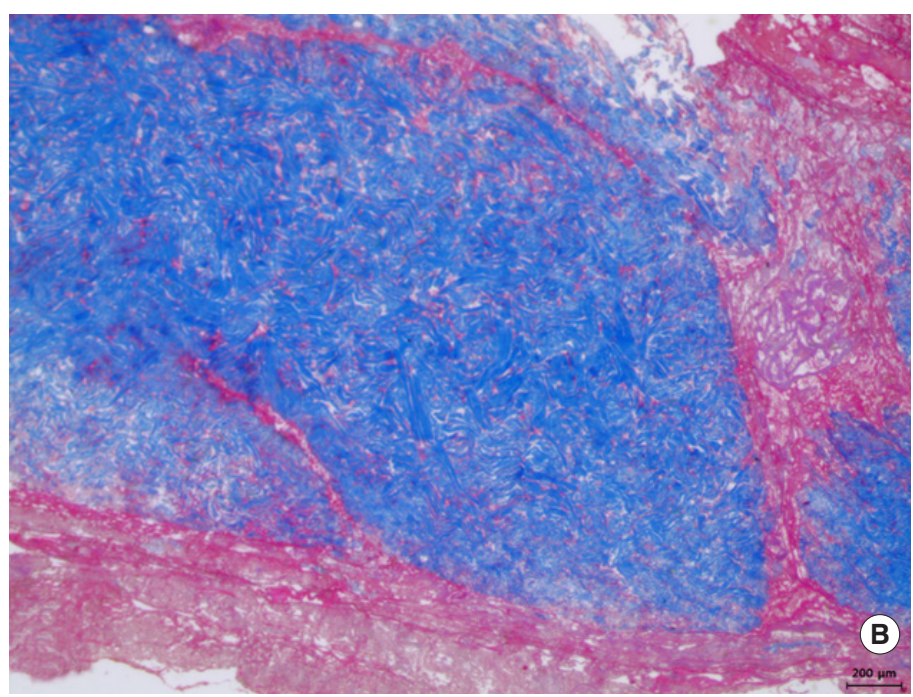

Fig. 3. Microscopic findings of resected acellular dermal matrix and tissue in a patient in whom meshed SurgiMend was used at 50 days postoperatively. (A) A large number of microvessels with red blood cells are observed near the SurgiMend (below) (H\&E, $\times 100)$. (B) Integrated tissues (red) are observed between meshes in the SurgiMend (blue) (Masson trichrome staining, $\times 40$ ).

\section{Histologic analysis}

In one patient, autologous breast reconstruction was conducted after removal of the implant due to malpositioning, and we were able to observe the relevant tissue during surgery. The operation was performed 50 days after meshed ADM placement, and extensive granulation was noted. Some sections of the collected tissue were stained with hematoxylin and eosin (H\&E) and Masson trichrome. Integration of microvessels with red blood cells was observed on H\&E staining. Masson trichrome staining revealed tissue integration with the ADM mesh (Fig. 3).

\section{Patient satisfaction}

When patient satisfaction was surveyed at least 1 year postoperatively, high scores were reported for satisfaction in terms of the shape, texture, symmetry, pain, and overall satisfaction on a scale of 1-5. The scores were $4.3 \pm 0.8,4.1 \pm 0.6,4.7 \pm 0.7,4.5 \pm 0.7$, and $4.4 \pm 1.1$, respectively, in the control group, whereas they were $4.3 \pm 0.3,4.0 \pm 1.2$, $4.6 \pm 0.5,4.2 \pm 0.6$, and $4.3 \pm 0.8$, respectively, in the experimental group. Although no statistical significance was observed in terms of satisfaction between the two groups, the average score was high (Table 3).

\section{DISCUSSION}

In this study, it was found that the use of meshed SurgiMend for DTI breast reconstruction resulted in high patient satisfaction (Fig. 4), and that the complication rate was not higher than that observed using conventional methods. In addition, a histological evaluation also confirmed that vessel and tissue integration was achieved between the meshes. This finding is consistent with the intention of using meshed SurgiMend to facilitate biointegration.

SurgiMend (TEI Biosciences Inc.), which is produced from fetal bovine dermis and is mainly composed of type I/III collagen, is commonly used worldwide in implant-based breast reconstructions due to its superiority in terms of tensile strength, suture retention strength, and tear resistance compared to other ADMs produced from porcine tissue with similar thickness [16]. It is sterilized through ethylene oxide. The preservation process allows to be 


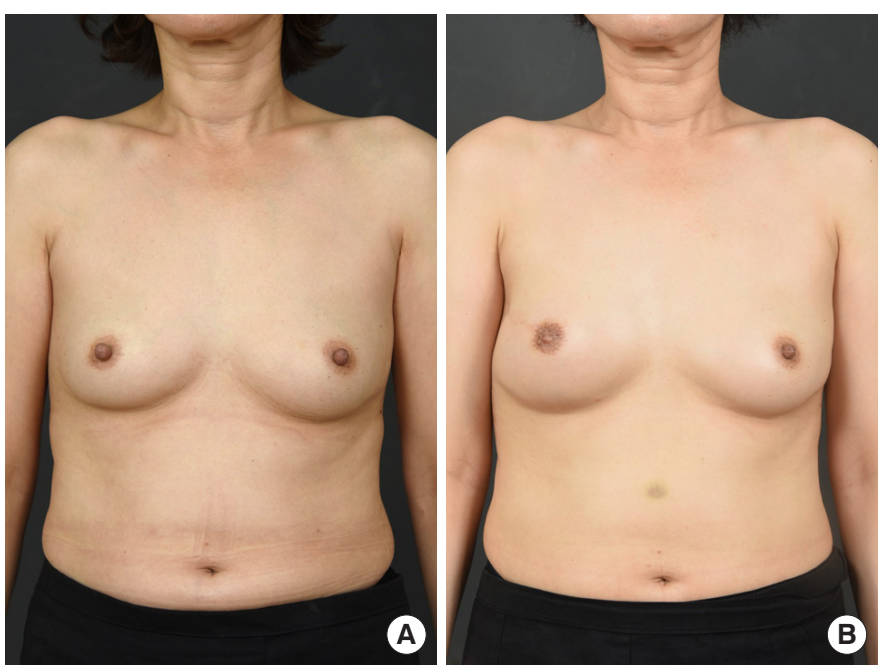

Fig. 4. Photos of a 53-year-old patient with breast cancer. (A) Preoperative photograph. (B) Postoperative follow-up photograph taken 1.5 years after the procedure using meshed SurgiMend.

stored at room temperature and then hydrated intraoperatively in room-temperature saline for around 60 seconds [22]. Products with various thicknesses are commercially available, and the SurgiMend 1.0 selected in this study had a thickness of about $1 \mathrm{~mm}$. None of the other ADM products in use at the authors' hospital were equally thin, and SurgiMend was selected for the study because it was suitable for meshing with a skin mesher.

Meshing ADM is expected to make it wider, which enables a surgeon to reduce the amount of ADM that is used in an operation. Zammit et al. [23] reported that the area of ADM was increased by about $50 \%$ by meshing it at a ratio of 1:1.5 using a skin mesher. In Korea, patients generally pay about $36 \mathrm{USD} / \mathrm{cm}^{2}$ for $\mathrm{ADM}$ such as SurgiMend. Therefore, using a smaller amount of ADM and enlarging it by meshing it will reduce patients' financial burden.

As a skin graft is a basic skill in reconstructive surgery, many medical institutions are already equipped with skin meshers. Therefore, creating meshed $\mathrm{ADM}$ does not take much time or require costs to purchase additional equipment. However, unlike SurgiMend, many other ADMs are difficult to insert into the mesher because of their thickness, making it impossible to produce meshed types. In addition, the finished products when ADM is fenestrated are limited in terms of the proportional increase of the surface area or the elongation achieved compared to what is possible using a mesher. A meshed ADM product, called SurgiMend PRS Meshed, is on the market, but it is not currently available in Korea. Therefore, it is more advantageous to fabricate meshed $\mathrm{ADM}$ using a mesher.

Meshing within the limits that ADM can withstand makes the $\mathrm{ADM}$ more adherent to the surface of the implant and easier to handle, but the strength of the matrix can be weakened as the mesh ratio increases. Nonetheless, Maisel Lotan et al. [24] reported that the mesh could withstand 10 times more strength until it was torn when meshed at a 1:2 ratio; therefore, breast reconstruction can be performed using that ratio. In the present study, the ADM was meshed at a 1:1.5 ratio, and it is expected that it has less impact on ADM strength because it enlarges when meshed at 1:2. Therefore, meshing with 1:1.5 ratio is also considered sufficient for ADM to withstand sufficient force and to be used in breast reconstruction surgery.

Hagarty et al. [25] reported that the use of meshed ADM in 192 cases in breast reconstructions involving a tissue expander was advantageous in terms of postoperative drain duration, hospitalization period, complications such as seroma, and frequency of painkiller use. In this study, the seroma rate was lower in patients who underwent DTI breast reconstruction using meshed SurgiMend than in those who underwent surgery using fenestrated SurgiMend, but the difference was not statistically significant. In this study, there was no statistically significant difference in preoperative breast volume and mass excised during mastectomy between the experimental group and the control group $(\mathrm{P}=0.090$ and $\mathrm{P}=0.061)$, but the mean values showed a tendency to be somewhat different, which could affect the seroma rate. Frey et al. [26] reported that a higher mastectomy weight and a larger breast volume were associated with a higher seroma rate.

Cottler et al. [12] reported that although fenestrating ADM promotes biointegration, additional studies are needed to identify the appropriate distance or number of fenestrations. Additional studies with a larger sample size using various methods, such as different ratios of skin meshing or directly using a blade for fenestration, will help to determine the appropriate distance and the number of fenestrations and to minimize the complications in patients.

The reported incidence of red breast syndrome varies widely across studies, from $1.7 \%$ to $14.3 \%$ [27-29]. In this study, red breast syndrome occurred in $12.5 \%$ and $15.0 \%$ of patients in the experimental group and the control group, respectively, which is slightly higher, but similar to the rates reported previous studies. Red breast syndrome was defined as local erythema appearing at the surgical site without systemic signs of infection after surgery. In this study, it is possible that an adequate differential diagnosis of local inflammation or infection was not performed. Some reports have stated that bacterial biofilm was observed in the ADM of patients with red breast syndrome [22], but the absence of biofilm in the absence of red breast syndrome was not confirmed, and only a single ADM was studied. Therefore, further research is required.

In this study, most patients underwent follow-up for more than 24 months. In three patients, the follow-up period was relatively short, about 5-7 months. Salzberg et al. [30] reported that there were no long-term complications during a lengthy follow-up of a patient who underwent DTI breast reconstruction using ADM. Therefore, it can be assumed that the majority of problematic complications will occur within a few months of surgery, and consequently that most of the complications of the patients in this study 
were identifiable despite the relatively short follow-up.

A limitation of this study is that it was impossible to directly compare biointegration between the two groups because autologous breast reconstruction was completed in only one patient who underwent DTI breast reconstruction. Further in vitro studies are required. The authors will evaluate the outcomes of this technique by following a larger number of patients for a longer period of time.

In conclusion, using meshed SurgiMend in implant-based breast reconstruction led to a similar frequency of complications as using non-meshed SurgiMend, and the rate of seroma was low. Furthermore, patient satisfaction was high and biointegration in the meshed tissues was confirmed. Thus, using meshed SurgiMend in DTI breast reconstruction is a useful surgical technique.

\section{NOTES}

\section{Conflict of interest}

No potential conflict of interest relevant to this article was reported.

\section{Ethical approval}

The study was approved by the Institutional Review Board of Kyungpook National University Hospital (IRB No. 2020-03-006) and performed in accordance with the principles of the Declaration of Helsinki.

\section{Patient consent}

The patients provided written informed consent for the publication and the use of their images.

\section{ORCID}

Pil Seon Eo

Joon Seok Lee

Jeong Woo Lee

Kang Young Choi

Ho Yun Chung

Byung Chae Cho

Jeeyeon Lee

Ho Young Park

Jung Dug Yang https://orcid.org/0000-0003-1909-7298

https://orcid.org/0000-0002-1580-0487

https://orcid.org/0000-0003-4903-6066

https://orcid.org/0000-0002-7735-1939

https://orcid.org/0000-0001-7359-3044

https://orcid.org/0000-0002-9395-8896

https://orcid.org/0000-0003-1826-1690

https://orcid.org/0000-0003-2318-9806

https://orcid.org/0000-0002-9040-4724

\section{REFERENCES}

1. Panchal H, Matros E. Current trends in postmastectomy breast reconstruction. Plast Reconstr Surg 2017;140(5S Advances in Breast Reconstruction):7S-13S.

2. Schlenker JD, Bueno RA, Ricketson G, et al. Loss of silicone implants after subcutaneous mastectomy and reconstruction. Plast Reconstr Surg 1978;62:853-61.

3. Woods JE, Irons GB Jr, Arnold PG. The case for submuscular implantation of prostheses in reconstructive breast surgery. Ann Plast Surg
1980;5:115-22.

4. Biggs TM, Yarish RS. Augmentation mammaplasty: a comparative analysis. Plast Reconstr Surg 1990;85:368-72.

5. Puckett CL, Croll GH, Reichel CA, et al. A critical look at capsule contracture in subglandular versus subpectoral mammary augmentation. Aesthetic Plast Surg 1987;11:23-8.

6. Spear SL, Schwartz J, Dayan JH, et al. Outcome assessment of breast distortion following submuscular breast augmentation. Aesthetic Plast Surg 2009;33:44-8.

7. Hammond DC, Schmitt WP, O'Connor EA. Treatment of breast animation deformity in implant-based reconstruction with pocket change to the subcutaneous position. Plast Reconstr Surg 2015;135:1540-4.

8. Salzberg CA. Nonexpansive immediate breast reconstruction using human acellular tissue matrix graft (AlloDerm). Ann Plast Surg 2006; $57: 1-5$.

9. Spear SL, Seruya M, Clemens MW, et al. Acellular dermal matrix for the treatment and prevention of implant-associated breast deformities. Plast Reconstr Surg 2011;127:1047-58.

10. Zenn MR. Indications and controversies for implant-based breast reconstruction utilizing biological meshes. Clin Plast Surg 2018;45:5563.

11. Paydar KZ, Wirth GA, Mowlds DS. Prepectoral breast reconstruction with fenestrated acellular dermal matrix: a novel design. Plast Reconstr Surg Glob Open 2018;6:e1712.

12. Cottler PS, Olenczak JB, Ning B, et al. Fenestration improves acellular dermal matrix biointegration: an investigation of revascularization with photoacoustic microscopy. Plast Reconstr Surg 2019;143:971-81.

13. Wirth GA, Mowlds DS, Guidotti P, et al. Acellular dermal matrix fenestrations and their effect on breast shape. Eur J Plast Surg 2015;38: 267-72.

14. Martin JB, Moore R, Paydar KZ, et al. Use of fenestrations in acellular dermal allograft in two-stage tissue expander/implant breast reconstruction. Plast Reconstr Surg 2014;134:901-4.

15. Palaia DA, Arthur KS, Cahan AC, et al. Incidence of seromas and infections using fenestrated versus nonfenestrated acellular dermal matrix in breast reconstructions. Plast Reconstr Surg Glob Open 2015;3: e569.

16. Adelman DM, Selber JC, Butler CE. Bovine versus porcine acellular dermal matrix: a comparison of mechanical properties. Plast Reconstr Surg Glob Open 2014;2:e155.

17. Wells HC, Sizeland KH, Kirby N, et al. Collagen fibril structure and strength in acellular dermal matrix materials of bovine, porcine, and human origin. ACS Biomater Sci Eng 2015;1:1026-38.

18. Cheng A, Saint-Cyr M. Comparison of different ADM materials in breast surgery. Clin Plast Surg 2012;39:167-75.

19. Ganske I, Hoyler M, Fox SE, et al. Delayed hypersensitivity reaction to acellular dermal matrix in breast reconstruction: the red breast syndrome? Ann Plast Surg 2014;73 Suppl 2:S139-43.

20. Wu PS, Winocour S, Jacobson SR. Red breast syndrome: a review of available literature. Aesthetic Plast Surg 2015;39:227-30. 
21. Danino MA, El Khatib AM, Doucet O, et al. Preliminary results supporting the bacterial hypothesis in red breast syndrome following postmastectomy acellular dermal matrix- and implant-based reconstructions. Plast Reconstr Surg 2019;144:988e-992e.

22. Ohkuma R, Buretta KJ, Mohan R, et al. Initial experience with the use of foetal/neonatal bovine acellular dermal collagen matrix (SurgiMend ${ }^{\mathrm{TM}}$ ) for tissue-expander breast reconstruction. J Plast Reconstr Aesthet Surg 2013;66:1195-201.

23. Zammit D, Kanevsky J, Meng FY, et al. Meshed acellular dermal matrix: technique and application in implant based breast reconstruction. Plast Aesthet Res 2016;3:254-6.

24. Maisel Lotan A, Ben Yehuda D, Allweis TM, et al. Comparative study of meshed and nonmeshed acellular dermal matrix in immediate breast reconstruction. Plast Reconstr Surg 2019;144:1045-53.

25. Hagarty SE, Yen LL, Luo J, et al. Decreased length of postoperative drain use, parenteral opioids, length of stay, and complication rates in patients receiving meshed versus unmeshed acellular dermal matrix in 194 submuscular tissue expander-based breast reconstructions: a single-surgeon cohort study. Plast Reconstr Surg 2020;145:889-97.

26. Frey JD, Salibian AA, Karp NS, et al. The impact of mastectomy weight on reconstructive trends and outcomes in nipple-sparing mastectomy: progressively greater complications with larger breast size. Plast Reconstr Surg 2018;141:795e-804e.

27. Ortiz JA. Clinical outcomes in breast reconstruction patients using a sterile acellular dermal matrix allograft. Aesthetic Plast Surg 2017;41: 542-50.

28. Glasberg SB, Light D. AlloDerm and Strattice in breast reconstruction: a comparison and techniques for optimizing outcomes. Plast Reconstr Surg 2012;129:1223-33.

29. Hill JL, Wong L, Kemper P, et al. Infectious complications associated with the use of acellular dermal matrix in implant-based bilateral breast reconstruction. Ann Plast Surg 2012;68:432-4.

30. Salzberg CA, Ashikari AY, Koch RM, et al. An 8-year experience of direct-to-implant immediate breast reconstruction using human acellular dermal matrix (AlloDerm). Plast Reconstr Surg 2011;127:514-24. 